\title{
Rekonsiliasi Pemuda dengan Alam
}

\author{
Nency Aprilia Heydemans, Fienny Maria Langi \\ Program Studi Sosiologi Agama dan Program Studi Musik Gereja \\ Fakultas Seni dan Ilmu Sosial Keagamaan Institut Agama Kristen Negeri Manado
}

nncy_354@yahoo.com | fiennylangi@gmail.com

\section{ABSTRACT}

The earth is getting hotter. Extreme climate change occurred globally in the era of the industrial revolution 4.0. Global warming is a threat as well as human responsibility as the perpetrators of environmental damage. Waste and population growth threaten the function of ecosystem sustainability. From this issue, arises awareness for young people to reconcile with themselves and nature, through a green lifestyle. Green lifestyle is an effort of the youth to contribute, in order to save the ecology. This study's aim is to determine the sensitivity of the youth of the Evangelical Christian Church in Minahasa (GMIM) to environment, by carrying a tumbler as part of a green lifestyle. This research uses a qualitative method, with a descriptive approach through ecological studies. The data obtained are primary data through observation and in-depth interviews with 4 GMIM youths aged 16-30 years, then secondary data through books, journals, and the internet. The results of this study indicates that the green lifestyle of the youth of GMIM by carrying a tumbler, can reduce plastic waste, which also supports the success of youth reconciliation with nature. Apart from oneself, Minahasa social and cultural factors also play a role in preserving the environment.

KEYWORDS Green lifestyle | Reconciliation | Ecology | Youth

\section{PENDAHULUAN}

Sampah plastik merupakan bahan berbahaya bagi kelangsungan makhluk hidup baik yang menjadi indikator pencemaran laut, darat maupun udara. Indonesia menjadi negara penyumbang sampah plastik terbesar kedua di dunia setelah Cina. Program Lingkungan PBB yaitu United Nations Environment Programme (UNEP 2014) menuturkan kerugian yang timbul akibat pembuangan sampah plastik dapat mencapai USD 13 miliar dolar atau sekitar 153 triliun rupiah pertahun. erarti produksi sampah plastik tiap tahun meningkat sesuai gaya hidup manusia yang turut mempengaruhi kondisi ekonomi, lingkungan hidup dan sosial.

Sejak mengenal peradaban ribuan tahun lalu, manusia selalu berusaha meningkatkan kualitas hidupnya. Schawab (2016) menjelaskan tentang revolusi industri yang melanda benua Eropa dan menjalar sampai ke Amerika pada tahun 1760-1840. Manusia mulai menciptakan mesin-mesin baru untuk digunakan dalam bidang pertanian dan perkebunan. Semuanya ini tidak lepas dari penemuan mesin uap dalam bidang ilmu pengetahuan dan teknologi bak sebuah logam yang memiliki dua sisi yang berbeda, yaitu dampak positif dan negatif. Dampak positif manusia dapat dengan praktis dan efisien melakukan pekerjaan. Di sisi lain dapat mengeruk hasil kekayaan alam sebanyak-banyaknya dalam waktu singkat dan manusia berangsur-angsur menjadi objek, tidak lagi menjadi subjek yang mengendalikan kemajuan 
teknologi modern ini (Wardhana 2004).

Pada abad ke-19, muncul penemuan ilmiah perkembangan listrik yang mengubah gaya hidup manusia. Ini disebut revolusi industri kedua (Dahler dan Budianta 2004). Pada tahun 1960, muncullah komputer dan internet yang menjangkau lapisan masyarakat di seluruh dunia (Schawab 2016). Khusus penggunaan plastik, tepatnya pada tahun 1975 diperkenalkan oleh Montgomery Ward, Sears, J.C. Penny, Jodan Marsh dan toko-toko retail besar lainnya yang berkembang luar biasa penggunaannya (Marpaung dan Widiaji 2009). Revolusi industri ketiga memiliki kemampuan tekologi yang canggih untuk memproduksi lebih banyak. Produksi menjadi kekuatan luar biasa hanya menghitung jam, banyak produksi yang dihasilkan misalnya memproduksi plastik dengan jumlah banyak. Dalam prosesnya, perkembangan teknologi menjadi semakin pesat dengan munculnya inovasi teknologi dalam revolusi industri 4.0 yang berefek pada susunan manusia pasar global (Kasali 2017). Sampah plastik yang dihasilkan berjumlah 220 juta ton/tahun pada tahun 2005 dan terus mengalami kenaikan secara signifikan. Itu berarti dengan penduduk Indonesia 327 juta jiwa diperkirakan tahun 2025 prediksi sampah plastik dapat mencapai 130.000 ton per hari (Puspita 2018).

Dewasa ini timbul kekhawatiran manusia atas masalah lingkungan yang dapat mengurangi kualitas dan kenyamanan hidup misalnya adanya sampah, banjir, efek rumah kaca, hujam asam, tanah longsor, kemiskinan, ancaman penyakit, udara panas, kehancuran berbagai spesies dan penebangan hutan (Rusbiantoro 2008). Muncul Konferensi Tingat Tinggi Bumi di Rio de Janeiro 1992 yang membahas perdamaian dan keutuhan ciptaan menjadi bagian Dewan Gereja-gereja se-Dunia. Ini dihubungkan dengan eko-teologi dalam misi penciptaan melalui upaya kehidupan berkelanjutan (Granberd-Michaelson 1997).

Rekonsiliasi merupakan perbuatan memulihkan hubungan persahabatan pada keadaan semula (KBBI 2002: hal. 942). Rekonsiliasi ini dilakukan untuk memulihkan hubungan manusia dengan alam yang mulai rusak. Manusia bertanggungjawab atas kerusakan lingkungan global yang terjadi. Tahun 1997 muncul Protokol Kyoto sebagai perjanjian Internasional tentang lingkungan hidup yang diikuti oleh negara-negara berkembang dan negara-negara industri. Khusus negara-negara industri agar dapat menurunkan emisi gas 5\% dari tingkat emisi tahun 1990 untuk periode 2008-2012. Ini bertujuan untuk mengurangi emisi gas rumah kaca penyebab pemanasan global (Murdiyarso 2003).

Penyebab utama pemanasan global terjadi karena pola konsumsi dan gaya hidup manusia yang hedonis, materialis, egois yang berujung pada kerusakan ekosistem (Asiah 2008). Pemanasan global jika ditinjau dari kejadian disebabkan meningkatnya temperatur rata-rata pada lapisan atmosfer, meningkatnya temperatur air laut dan temperatur daratan (Susanta dan Sutjahjo 2007). Di Indonesia dampak langsung yang terasa adalah penggunaan bahan anorganik plastik yang sulit diuraikan oleh tanah dan air karena memerlukan waktu yang lama seperti kaleng aluminium memerlukan 80-100 tahun, plastik terurai 50-100 tahun, botol plastik 500-1000 tahun, sterofoam tidak dapat teruraikan (Fhai 2019). Ini menjadi perhatian bersama semua elemen masyarakat akan masalah ekologi khususnya penggunaan plastik sekali pakai perlu dikurangi mengingat sangat berbahaya bahkan bisa mengancam kehidupan manusia dan makhluk hidup lainnya yang berkembang biak (Wardhana 2004).

Menurut Susi Pudjiastuti, Menteri Kelautan dan Perikanan RI "Indonesia merupakan negara penyumbang sampah plastik ke lautan terbesar kedua di dunia, sampah plastik sangat berbahaya," (Pratama 2018). Sampah berkembang dalam kepadatan penduduk. Sampah yang dihasilkan $75 \%$ dari sampah organik dan $25 \%$ dari sampah anorganik. Sampah anorganik 
identik dengan sampah plastik yang sulit didegradasikan oleh alam. Plastik sampah berkembang begitu cepat karena konsumerisme. Saat ini industri mengeksplorasi sumber bahan mentah alam kemudian beralih ke bahan-bahan sintesis seperti kayu, wol, sutra, nilon, akrilik, katun yang jauh lebih murah, bisa digunakan berulang, ringan dan murah (Putra dan Yuriandala 2010). Dengan permasalahan lingkungan hidup yang sedang terjadi diharapkan kontribusi pemuda sebagai agent of change ikut berpartisipatif aktif dalam menjaga, mengelola dan bertanggung jawab akan ekologi ini. Generasi muda saat ini berada pada resiko malapetaka lingkungan global yang tidak bisa dihindari.

Gaya hidup hijau merupakan kesadaran dan sikap manusia untuk menjaga, melestarikan alam (Ardyanto 2016). Salah satu gaya hidup hijau adalah penggunaan tumbler sebagai solusi mengurangi sampah plastik. Pemuda membangun jejaring bersama gereja, pemerintah dan budaya Minahasa untuk melakukan rekonsiliasi alam dengan gaya hidup hijau. Sebagai konsekuensi, pemuda harus melakukan rekonsiliasi dengan menghormati alam sebagai sahabat terdekat. Budaya ramah lingkungan perlu digalakkan sejak dini.

\section{KAJIAN LITERATUR}

Kajian mengenai pemuda tidak bisa dipungkiri menarik dikaji dalam pendekatan ekologi melalui gaya hidup hijau. Pendekatan ini selalu menarik karena memunculkan perdebatan perspektif dalam memahaminya. Khalil, Purwoko, dan Pratomo (2016) melakukan penelitian tentang green open space di Aceh dan peran pemuda Aceh membuat tata ruang hijau kota yang ramah lingkungan. Gaya hidup hijau atau green lifestyle merupakan sebuah gaya hidup yang berdampak positif bagi kehidupan manusia dan alam. Dimulai dari tindakan kecil tetapi berdampak besar misalnya membawa tas setiap kali berbelanja, mengurangi penggunaan tisu dan kertas, membawa tempat makan, membawa tempat air minum (Aviani 2014). Gaya hidup hijau dimulai dari diri sendiri sebagai wujud kepedulian sosial dan alam.

Green lifestyle bisa juga dikaitkan dengan pengurangan botol plastik sekali pakai dengan penggunaan tumbler. Menurut Iklan Layanan Masyarakat (PSA) yang dibuat oleh Ade Inge Andhini (2019) manusia memerlukan delapan gelas air perhari sepanjang aktivitasnya. Oleh sebab itu, sampah plastik menjadi limbah terbesar yang dipakai manusia. Sampah botol plastik sekali pakai menjadi limbah berbahaya yang sulit terurai oleh tanah dengan membutuhkan waktu 450 tahun dan plastik yang ditemukan dalam laut bisa terurai sekitar 400 tahun. Bahayanya, setiap tahun delapan juta ton plastik dibuang manusia ke laut. Ekosistem biota laut terancam punah dan bisa mengganggu rantai makanan. Green Lifestyle akan menjadi populer jika dikampanyekan kepada semua pihak. Ini bertujuan agar masyarakat melakukan tindakan ramah lingkungan. Dalam buku Ecological Intelligence: Kecerdasan Ekologis, Goleman (2010) menuliskan banyak produk memberikan label "green" namun tidak konsisten menghadapi krisis ekologis. Muncul istilah "transparansi radikal" yang menjadikan konsumen mengambil keputusan secara cerdas saat membeli barang sehingga perusahan besar dapat memperbaharui bisnis pasar ke era baru ramah lingkungan. Seringkali konsumen menjadi korban informasi dari proses produksi, pengiriman barang, dan pembuangan barang.

Pemuda sebagai agen perubahan perlu memiliki paradigma pembangunan yang humanis, kreatif, inovatif untuk pembangunan berkelanjutan. Ini dapat mempengaruhi Sumber Daya Alam (SDA) menuju pada kualitas pembangunan lingkungan hidup berkelanjutan. Hal ini ditulis oleh Khalwani (2018) tentang pemuda dan lingkungan hidup dilihat dalam kerangka "Sustainable Development Goals" di Indonesia”. Pemuda memiliki skill, tanggung jawab, hak, karakter, kapasitas, aktualisasi diri, dan cita-cita pemuda. Sedangkan pembangunan kepemudaan menjadi proses memfasilitasi ke- 
giatan pemuda dalam bentuk kegiatan formal, semi-formal, maupun informal yang berpengaruh kualitas Indonesia ke depan, termasuk kualitas lingkungan hidupnya.

\section{METODE PENELITIAN}

Tulisan ini menggunakan metode kualitatif dengan pendekatan deskriptif untuk meneliti dan memahami makna sekelompok manusia pada masa sekarang (Sugiyono 2007). Penelitian ini berfokus pada pemuda yang membawa tumbler dalam aktivitas setiap hari. Tumbler menjadi gaya hidup hijau kaum pemuda melalui jejaring organisasi gereja, pemerintah dan budaya lokal. Oleh sebab itu, penelitian ini menggunakan studi ekologi dalam rangka memaknai pemuda sebagai subjek. Studi ekologi merupakan sebuah metode yang menganalisis hubungan antara manusia dan lingkungan hidup termasuk juga lingkungan sosial, ekonomi dan budaya. Metode ini mengarah pada ruang lingkup fenomena di mana setiap tindakan fisik manusia menempatkan hubungan lingkungan dan manusia sebagai agen perubahan (Rustandi 2011).

Pemilihan informan dilakukan secara purposif dan disesuaikan dengan kebutuhan penelitian (Creswell 2015). Salah satunya berdasarkan Undang-undang No. 40 tahun 2009 bahwa pemuda berusia 16 - 30 tahun. Karakteristik informan difokuskan kepada pemuda GMIM yang berdomisili di daerah Bitung, Manado, dan Tomohon. Ketiga daerah ini telah mencanangkan penggunaan tumbler sekaligus memiliki komitmen untuk mengurangi wadah plastik sekali pakai. Penelitian ini terdiri atas empat informan, yaitu: Pricillia Tangel (PT, 28 tahun) berdomisili di Manado sebagai Ketua Pemuda Sinode GMIM periode 2018-2022, Feiby Atara (FA, 29 tahun) berdomisili di Bitung sebagai Komisi Sinode GMIM Bidang Sosial Budaya dan Lingkungan Hidup, Toar Poluan (TP, 30 tahun) sebagai Komisi Pelayanan Pemuda Sinode GMIM Bidang Kewirausahaan sekaligus Ketua Wilayah Tomohon 2, dan Boby Wehan- touw (BW, 28 tahun) sebagai Penatua Pemuda GMIM Siloam Tara-Tara.

Observasi dilakukan pada tanggal $14 \mathrm{Ma}-$ ret sampai 27 Juli 2019. Adapun manfaat dilakukannya wawancara yaitu dapat menggali informasi berkaitan dengan kebiasaan membawa tumbler sebagai gaya hidup hijau dan pengalaman dalam aktivitas kegiatan ramah lingkungan. Dengan adanya kedua teknik pengumpulan data ini maka penelitian mengarah pada pemuda sebagai agen perubahan dalam konteks budaya lokal serta kontribusi pemuda menghadapi kerusakan lingkungan hidup skala global.

\section{KERANGKA TEORI}

Perspektif Pemanasan Global

Dalam bukunya, "Etika Bumi Baru," Borong (2000) menyatakan bahwa pemanasan global terjadi berkaitan dengan sikap manusia yang kurang memperhatikan norma-norma moral dihubungkan dengan lingkungan hidupnya dan sesama manusia. Sikap yang menonjol yaitu eksploitatif dan destruktif terhadap sumber daya alam. Dari sikap manusia inilah maka muncul perubahan iklim ekstrem. Menurut Borong, umat terpanggil menjalankan misi dalam tugas ibadah, diakoni dan oikumene dalam rangka pelayaanan baik kepada manusia maupun kepada lingkungan hidup. Di sisi lain, krisis lingkungan hidup terjadi karena ulah manusia yang tidak bertanggung jawab, budaya salah kaprah untuk kepentingan hidupnya. Akibatnya, suhu bumi makin memanas. Oleh karena itu, perlu ada kesadaran dari manusia untuk membentuk sistem pemikiran ekologis melalui sikap ramah lingkungan (Chang 2001).

Salah satu penyebab terjadinya pemanasan global berasal dari aktivitas dan kebutuhan manusia itu sendiri dengan gaya hidup instan, modern dan canggih. Tidak bisa dihindari bahwa manusia mulai menghancurkan sumber daya alam yang menjadi bahan makanan pokok. Kecurigaan ini disebut ecological suicide (ecocide) yang berarti membunuh diri sendiri secara tidak langsung dengan merusak atau menghan- 
curkan lingkungan (Diamond 2005: 7). Lebih dari 100 ilmuwan di seluruh dunia bergabung dalam organisasi Intergovernmental Panel on Climate Change (IPCC) dilibatkan secara langsung melalui diskusi pemanasan global. Pemanasan global merupakan peningkatan kadar gas rumah kaca yang berakibat suhu bumi naik. Pemanasan global terjadi begitu cepat seiring dengan aktivitas manusia yang tidak ramah lingkungan. Ada beberapa dampak dari pemanasan global yaitu muncul perubahan iklim dan cuaca ekstrim; Kenaikan permukaan air laut; pengaruh terhadap kesehatan manusia dengan aneka penyakit yang muncul; Pengaruh terhadap pertanian, kehutanan, tumbuh-tumbuhan dan hewan. Pengaruh ini memiliki beragam skala antara lain: jangka pendek dan jangka panjang yang dirasakan secara global (Rusbiantoro 2008).

\section{Keberlanjutan Ekologi}

Wooster (1995) menyatakan bahwa semua negara dapat meninggalkan paradigma pembangunan berkelanjutan dengan menerapkan kebijakan keberlanjutan ekologi melalui perlindungan spesies, ekosistem, keanekaragaman kehidupan, komunitas dengan mempertahankan keanekaragaman hayati yang masih dimiliki oleh alam. Melestarikan warisan alam dapat memberi nilai ekonomis, nilai estetika alam, nilai penghormatan, dan nilai dari kehidupan itu sendiri yang menjadi sebuah fenomena, sulit untuk dijelaskan dengan akal budi manusia. Sejak dahulu masyarakat tradisional hidup dengan kekayaan alam yang melimpah tanpa merusak alam. Tidak bisa dipungkiri bahwa alam memberikan kehidupan yang begitu bermanfaat bagi manusia sehingga manusia perlu arif menjaga alam dengan strategi mempertahankan keutuhan ekosistem yang menjadi tempat kehidupan makhluk hidup. Inilah dinamakan sebagai keberlangsungan ekologi (Keraf 2002). Ini bukan hanya menjadi tugas tanggungjawab sepihak tetapi melibatkan stakeholders demi keutuhan alam yang menjadi bagian integral dari proses kehidupan makhluk hidup.
(Naess 1993) menawarkan keberlanjutan ekologi akan benar tercapai jika ada perubahan mendasar dari kebijakan politik ekonomi menyangkut pertumbuhan ekonomi dan gaya hidup masyarakat yang konsumtif. Yang dibutuhkan dalam strategi ini adalah membangun kesadaran masyarakat lokal untuk mempunyai kehidupan ekonomi ramah lingkungan dan juga dari sisi sosial-budaya. Gaya hidup kearifan lokal ini tidak bertitik tolak pada produksi dan konsumsi yang berlebihan tetapi menurut Naess (1993:88) "simple in means, but rich in ends" itu berarti bukan having more melainkan being more. Untuk memahami perspektif keberlanjutan ekologi perlu dilihat dalam konteks kontribusi manusia bagi terciptanya keselarasan global. Dalam konteks ini Maathai (2005) menyampaikan tiga R yaitu Reduce, Reuse dan Recycle. Hal ini menjadi tindakan manusia untuk tidak menyerah mengubah gaya hidup hijau yang lebih ramah lingkungan, mengurangi penggunaan bahan bakar fosil, tidak boros energi di mulai dari tindakan hidup sederhana, mencintai makhluk hidup, kenali tetangga dan membangun jejaring. Hal yang sama juga terlihat dari kontribusi pemuda yang ada di Indonesia lebih khusus di Bitung, Manado dan Tomohon. Data pemuda tahun 2019 Gereja Masehi Injili di Minahasa (GMIM) berjumlah 133.725 pemuda yang terdiri 55.840 perempuan dan 77.885 laki-laki yang berusia 16-30 tahun. Pada data ini, pemuda menjadi bagian dari misi penyelamatan bumi dengan mengurangi kemasan botol plastik sekali pakai. Hal ini menjadi program dan aksi bersama pemuda dalam berpikir global bertindak lokal melalui penggunaan tumbler dalam aktivitas bekerja, kuliah, bertamasya, ibadah dan kegiatan lainnya.

\section{TEMUAN DAN ANALISIS}

Bagian ini memaparkan hasil penelitian dan analisis di lapangan yaitu kepekaan rekonsiliasi terhadap lingkungan yang dilakukan pemuda GMIM dalam aksi melalui gaya hidup hijau. 
Kepekaan Rekonsiliasi terhadap Lingkungan Hidup dalam Praktik Membawa Tumbler Sebagai Gaya Hidup Hijau Melalui Narasi Empat Pemuda

"Saya peduli dengan lingkungan alam yang mulai rusak. Oleh karena itu, berdasarkan hasil konsultasi pemuda GMIM tahun lalu, maka gaya hidup pemuda diarahkan untuk menggunakan tumbler sejak bulan Februari 2019. Ini mulai dijabarkan dalam renungan Obor Pemuda, khotbah, ibadah, dan terlebih aksi kesadaran diri sendiri menggunakan gelas plastik refil. Aksi ini didukung oleh gereja, pemerintah dan terdapat rumah kopi yang menyediakan air minum isi ulang gratis bagi pengunjungnya." - PT ( 28 tahun).

Informan di atas menyampaikan bahwa kepedulian ini bertumbuh dari kesadaran diri sendiri untuk peduli dengan lingkungan alam. Pemudi ini merupakan ketua pemuda Sinode GMIM periode 2018-2022. Bersama dengan kedua orang temannya, FA (29 tahun) dan TP (30 tahun) menjadi komisi pelayanan pemuda Sinode GMIM. Melalui program bersama tentang "A world without plastic waste, reject, reduce, recycle, reuse" dengan mengajak seluruh pemuda untuk hidup ramah lingkungan melalui penggunaan tumbler. Slogan yang dibuat dalam cover belakang renungan Obor Pemuda yakni "Makin asyik tanpa plastik." Slogan tersebut terletak di samping gambar tumbler.

Dari penuturan di atas dapat dipahami bahwa menjadi pemimpin gereja perlu memberikan teladan dalam mengatasi krisis lingkungan hidup yang sedang terjadi. Melalui pengurangan sampah plastik, berarti pemuda sedang berkontribusi melakukan aksi green lifestyle. Peran pemuda ini demi keberlangsungan ekologi (Keraf 2002). Ini melibatkan stakeholders demi keutuhan alam mengurangi dampak dari pemanasan global dan perubahan iklim yang sedang dirasakan oleh negara berkembang.

Menurut FA, pengurangan sampah plastik telah didukung oleh pemerintah kota Bitung yang sudah berlangsung selama dua tahun. Pemerintah kota Tomohon sudah melakukan- nya setahun yang lalu bersamaan dengan kota Manado. Dukungan program pemuda sinode GMIM ikut andil dalam pengurangan sampah plastik yang dapat mengakibatkan polusi udara, polusi tanah, dan polusi air. Baik program pemerintah maupun gereja memiliki seruan yang sama yaitu penggunaan botol minum plastik berulang kali (tumbler).

"Adanya seruan dari pemerintah kota Bitung sudah dijalankan dua tahun yang lalu, kota Tomohon dan Manado setahun yang lalu untuk penggunaan tumbler mengurangi sampah plastik. Dalam kegiatan ibadah pemuda gereja seperti ibadah Paskah pemuda 2019, ibadah pemuda jemaat sudah menggunakan dispenser refill dan gelas kaca." (FA, 29 tahun).

FAmengatakan bahwa dukungan gereja dalam kegiatan ibadah sudah memberikan teladan yang baik bagi pemuda. Ini menjadi bukti serius bahwa pemuda menjadi garda terdepan didukung oleh gereja dan pemerintah. Terkait dari program ini, FA berkomitmen untuk menjalankan green lifestyle dimulai dari diri sendiri dan didukung oleh orang tua. FA merupakan seorang pemudi yang menjabat sebagai Komisi Sinode GMIM Bidang Sosial Budaya dan Lingkungan Hidup. Oleh karena itu, perlu ada kesadaran diri sendiri sambil membangun jejaring dengan melakukan rekonsiliasi alam melalui sikap ramah lingkungan (Chang 2001).

Sementara itu, TP seorang pemuda kelahiran Tomohon merupakan Komisi Pelayanan pemuda Sinode GMIM Bidang Kewirausaan dan Ketua Wilayah Tomohon 2 ini mengaku bahwa kepedulian pemuda sudah ditunjukkan dalam renungan, ibadah wisata pemuda wilayah Tomohon 2 yang diselenggarakan di Kombi bahkan hadiah yang disediakan oleh panitia berupa tumbler bagi para peserta yang menang. Kegiatan ramah lingkungan sudah berlangsung sepanjang tahun berjalan ini. Aksi ini menjadi dampak positif bagi pemuda dalam kegiatan yang berlangsung. Mengingat Kota Tomohon disebut sebagai kota bunga yang memberi nilai estetika alam yang sejuk. 
"Setiap kegiatan di luar rumah saya membawa tumbler. Akan tetapi, sebagai seorang pemuda laki-laki ada tantangan yang dihadapi yakni budaya malu. Apalagi tumbler dipegang dan tidak diisi di dalam tas. Ada rasa malu, setengah mati. Begitu juga dengan ibadah pemuda wilayah Tomohon 2 masih ada dua jemaat yang menyediakan air minum gelas plastik sekali pakai. Kemudian ada dalam ibadah menggunakan bambu yang menjadi budaya Minahasa sebagai alat air minum." TP (30 tahun).

TP mengatakan bahwa bagi kaum laki-laki ada perasaan malu membawa tumbler. Sebagai contoh dalam ibadah pemuda atau kegiatan kepemudaan ada yang tidak membawa tumbler. Ini disebabkan sikap saling mengejek antar teman. Menurut TP masih ada dalam ibadah pemuda menggunakan gelas plastik sekali pakai. Ini menjadi perhatian bersama untuk kembali ke gelas kaca dan atau bisa membawa tumbler. Meskipun sudah disosialisasikan namun belum ada kepekaaan ekologis dari diri sendiri untuk menjaga dan berekonsilasi dengan alam. Sebagai seorang pemimpin ia menampilkan sikap ramah lingkungan dengan membawa tumbler sebagai solusi mengurangi sampah dan hemat secara ekonomi.

Gaya hidup kearifan lokal Minahasa perlu ditonjolkan dengan menghargai alam sebagai bagian dari ciptaan-Nya. Bambu yang sudah dipotong sesuai ukurannya sudah dikenal oleh orang Minahasa sebagai alat air minum yang bisa dipakai berulang kali bahkan ramah lingkungan. Namun sangat disayangkan penggunaan bambu sangat sulit ditemui karena banyak ditebang oleh masyarakat. Jikapun ada, hanya dalam acara tertentu seperti ibadah atau pesta pernikahan. Kearifan lokal budaya Minahasa perlu dikembangkan dan dilestarikan sebagai tindakan hidup sederhana, mengasihi lingkungan, hemat air dan mengurangi botol plastik sekali pakai.

Sementara itu BW seorang pemuda yang berasal dari Tomohon menuturkan masih kurang kesadaran diri, belum terbiasa dan ada rasa gengsi yang dialami bersama teman lain- nya. Ini menjadi tantangan pemuda masa kini. Gengsi ini muncul karena ada anggapan bahwa membawa tumbler seperti gaya anak-anak dan tidak gaul. Bagi kaum laki-laki yang membawa tumbler seringkali diletakkan ke dalam tasnya agar lebih aman dan tidak diejek teman sebaya. Sebagaimana kutipan wawancara berikut ini:

"Saya seringkali lupa membawa tumbler, ka-
lau itupun dibawa pasti dimasukkan ke da-
lam tas agar tidak dilihat oleh teman-teman.
Sebagai pemuda, membawa tumbler seperti
gaya anak-anak. Masih ada rasa gengsi yang
dirasakan. Namun dalam kegiatan pemuda
penggunaan gelas kaca sudah dimulai sejak
bulan Desember 2018." - BW ( 28 tahun).

Menurut BW di setiap kegiatan pemuda sudah menggunakan gelas kaca dan menghentikan penggunaan gelas plastik sekali pakai. Penggunaan gelas kaca sudah dilakukan sejak Desember 2018. Penggunaan ini sesuai dengan program yang disampaikan baik pemerintah maupun gereja. BW mulai berdamai dengan diri sendiri untuk menghadapi tantangan dengan tidak lupa membawa tumbler, keluar dari ejekan teman yang tidak mendidik, dan hidup hemat energi air maupun hemat biaya.

Jika menilik dengan penyampaian Asiah (2008) bahwa penyebab utama pemanasan global yaitu pola konsumsi manusia dan gaya hidup hedonis, materialis, egois yang mengarah pada kerusakan ekosistem global. Maka pemuda harus menghadapi tantangan terbesar dalam hidupnya yaitu diri sendiri di mana perlu membiasakan diri membawa tumbler. Tantangan kedua yakni ejekan dari teman. Ada tanggapan bahwa membawa tumbler seperti gaya anak-anak. Itu berarti, generasi muda sering menganggap bahwa generasi sebelumnya ketinggalan zaman (Naafs dan White 2012). Andhini (2019) mengatakan bahwa manusia membutuhkan delapan gelas air perhari. Oleh karena itu, sampah botol plastik menjadi limbah terbesar di dunia yang dikonsumsi manusia. Dalam dilema ini BW perlu dibekali dengan pemahaman keberlangsungan ekologi bagi setiap pemuda untuk menghadapi iklim yang se- 
makin ekstrem. Green Lifestyle bertujuan agar pemuda melakukan tindakan ramah lingkungan sejak dini. Dimulai dari dalam keluarga, gereja dan masyarakat. Gaya hidup pemuda ini tidak sebanding dengan gaya hidup masyarakat industri di Eropa dan Amerika. Akan tetapi jika dimulai dari diri sendiri, diwariskan kepada orang lain melalui kampanye atau program-program yang ada maka akan berdampak positif dengan skala lokal. Oleh karena itu, pemuda/i PT, FA, dan TP sedang berupaya untuk menerapkan in loco, artinya berpikir global dengan tindakan lokal ramah lingkungan.

\section{KESIMPULAN}

Gaya hidup hijau merupakan upaya melakukan aksi dan ikut andil meminimalisir kerusakan lingkungan akibat ulah manusia yang tidak ramah lingkungan, Ada tantangan yang dihadapi baik dari diri sendiri maupun dari teman sejawat. Tantangan yang dihadapi dalam penelitian ini muncul ketika ada gengsi dari diri sendiri, sifat malu diikuti faktor tidak sengaja yakni lupa membawa tumbler. Sementara itu dalam perspektif pemuda bahwa orang yang membawa tumbler seperti gaya anakanak. Akan tetapi bagi pemuda lainnya memahami tumbler sebagai botol plastik yang bisa dipakai berulang kali, ramah lingkungan, mengurangi sampah plastik, dapat menghemat air dan menghemat keuangan. Strategi aksi lokal dapat menyentuh aspek ekonomi, sosial dan budaya. Kepedulian ekologi harus dimulai dari diri sendiri, kemudian melakukan aksi bersama dengan pemuda lainnya dalam kegiatan gereja, masyarakat, dan kegiatan lainnya.

\section{DAFTAR PUSTAKA}

Andhini, Ade Inge. 2019. "Green Lifestyle, Mengurangi Sampah Plastik dengan Tumbler." Diakses dari https://www.ceraproduction.com/ publication pada 20 Juli 2019.

Ardyanto, Anto. 2016. "Apa itu Green Lifestyle atau Gaya Hidup Hijau?” Diakses dari http://www. celotehhijau.com/2016/publication pada 24 Juli 2019.

Asiah, Abu AR. 2008. Global Warning: Sebuah Isyarat Dekatnya Akhir Zaman dan Kehancuran Dunia. Surakarta: Granada Mediatama.

Aviani, Triastuti. 2014. "Penerapan Green Lifestyle di Griya Lembah Keluarahan Abadijaya Kecamatan Sukmajaya Depok Jawa Barat." Skripsi. Universitas Islam Negeri Syarif Hidayatullah.

Borrong, Robert P. 2000. Etika Bumi Baru. Jakarta: BPK Gunung Mulia.

Chang, William. 2001. Moral Lingkungan Hidup. Yogyakarta: Kanisius.

Climate Change Secretariat (UNFCGC). 2005. Caring for Climate: A Guide to the Climate Change Convention and the Kyoto Protocol. Germany: UNFCCG.

Cresswell, Jhon W. 2015. Research Design. London: Sage Publication.

Dahler, Frans dan Eka Budianta. 2004. Pilar Peradaban Manusia. Yogyakarta: Kanisius.

Derr, Thomas Sieger. 1973. Ecologi and Human Liberation. Geneva: World Council of Churches.

Diamond, Jared. 2005. Collaps: How Sociaties Choose to Fail or Succeed. New York: Viking-Pengain books.

Deane-Drummond, Celia. 2006. Teologi dan Ekologi: Buku Pegangan. Jakarta: BPK Gunung Mulia.

Fardiaz, Srikandi. 1992. Polusi Air dan Udara. Yogyakarta: Kanisius.

Fhai. 2019. "12 Jenis Sampah dan Waktu yang Dibutuhkan Terurai." Diakses dari https://www. hipwee.com./publication pada 25 Juli 2019.

Goleman, Daniel. 2010. Ecological Intelligence: Kecerdasan Ekologis. Jakarta: Gramedia Pustaka Utama. 
Granberg-Michaelson, Wesley. 1997. Menembus Ciptaan: Konferensi Tingkat Tinggi Bumi di Rio: Tantangan Bagi Gereja-gereja. Jakarta: BPK Gunung Mulia.

Kasali, Rhenald. 2017. Disruption. Jakarta: Gramedia.

Kamus Besar Bahasa Indonesia Edisi Tiga. 2002. Jakarta: Balai Pustaka.

Kerap, Sonny. 2002. Etika Lingkungan. Jakarta: Buku Kompas.

Khalil, Zakki Fuad, Agus Purwoko, dan Wahyu Ario Pratomo. 2016. "Peran Pemuda Dalam Meningkatkan Kelestarian Kawasan Ruang Terbuka Hijau Di Kota Banda Aceh.” Jurnal Ekonom, Vol 19 (1): 23-35.

Khalwani, Khulfi M. 2018. "Pemuda dan Lingkungan hidup dalam Kerangka "Sustainable Development Goals" di Indonesia." Diakses dari https://www.kompasiana.com/ publication pada 25 Juli 2019.

Maathai, Wangari. 2005. "Wangari Maathai's Other Initatives." Diakses dari http://www. greenbeltmovement.org/publication pada 24 Juli 2019.

Marpaung, G. S. dan Widiaji. 2009. Raup Rupiah dari Sampah Plastik. Jakarta: Pustaka Bina Swadaya.

Milne, Antony. 2006. Dunia di Ambang Kepunahan: Bencana-bencana yang Mengancam Umat Manusia, terj. J.B. Srijanto Jakarta: BPK Gunung Mulia.

Murdiyarso, Daniel. 2003. Protokol Kyoto: Implikasinya Bagi Negara Berkembang. Jakarta: Buku Kompas.

Murray John. 1990. The Epistle to the Romans: the English Text With Introduction, Exposition and Notes. Michigan: B. Eerdmans Publishing CO.

Naess, Arne. 1993. Ecology, Community and Lifestyle. Cambridge: Cambridge Univ. Press.

Naafs, Suzanne. and White Ben. 2012. "Intermediate Generations: Reflections on Indonesian Youth Studies". The Asia Pacific Journal of Anthropology 13(1):3-20.

Okanagan University College in Canada, Depart- ment of Geography. 1995. United States. Environmental Protection Agency (EPA). Washington: Climate Change.

Pratama, Akhdi Martin. 2018. "Susi: Indonesia Penyumbang Sampah di Laut Terbanyaak Kedua di Dunia." Diakses dari https://www. kompas.com/publication pada 20 Juli 2019.

Puspita, Sherly. 2018. "Indonesia Penyumbang Sampah Plastik Terbesar Kedua di Dunia." Diakses dari https://megapolitan.kompas.com./ publication pada 24 Juli 2019.

Putra, Hijrah Purnama dan Yebi Yuriandala. 2010. "Studi Pemanfaatan Sampah Plastik Menjadi Produk dan Jasa Kreatif." Jurnal Sains dan Teknologi Lingkungan. Vol 2 (1): 21-31.

Rusbiantoro, Dadang. 2008. Global Warming For Beginner. Yogyakarta: O2.

Rustandi, Arip. 2011. "Ruang Lingkup Geografi." Diakses dari https://geografi-arip.blogspot. com/2011/publication pada 24 Juli 2019.

Schawab, Klaus. 2016. The Fourth Industrial Revolution. Geneva: World Economic Forum.

Sessions, George. 1995. Deep Ecology for the 21st Century: Readings on the Philosophy and Practice of the New Environmentalism. Boston: Shambhala.

Sinode Am Gereja Hervormd Belanda. 1994. Taman Eden itu Semakin Tandus: Krisis Lingkungan Hidup dan Tanggung Jawab Gereja: Suatu Tinjauan Untuk Memenuhi Kebutuhan Pembahasan dalam Jemaat, terj. S.L. Tobing-Kartohadiprojo. Jakarta: BPK Gunung Mulia.

Susanta, Gatut dan Sutjahjo Hari. 2007. Akankah Indonesia Tenggelam Akibat Pemanasan Global?. Jakarta: Penebar Plus.

Sugiyono. 2007. Memahami Penelitian Kualitatif. Bandung: Alfabeta.

United Nations Environment Programme (UNEP). 2014. "Plastic Waste Causes Financial Damage of US\$ 13 Billion to Marine Ecosystems Each Year as Concern Grows over Microplastics." Diakses dari https://www.unenvironment.org/publication pada 24 Juli 2019.

Wardhana, Wisnu Arya. 2004. Dampak Pencemaran Lingkungan. Yogyakarta: Andi. 
Widyahadi A, Siowarjaya Afra (ed) dkk. 2002. Rekonsiliasi Menciptakan Hidup Damai dan Sejahtera dalam Menggereja dan Bermasyarakat: Tinjauan dari Perspektif Religiusitas. Jakarta: Celesty Hieronika.

Wooster, Donald. 1995. The Shaky Ground of Sustainability dalam Geroger Sessions (ed.), Deep Ecology for the 21st century: Readings on the Philosophy and Practice of the New Environmentalisme. Boston: Shambhala. 